\title{
Processing relative clauses in Chinese
}

\author{
Franny Hsiao, Edward Gibson* \\ Massachusetts Institute of Technology, Cambridge, MA, USA
}

Received 28 February 2003; accepted 30 May 2003

\begin{abstract}
This paper reports results from a self-paced reading study in Chinese that demonstrates that object-extracted relative clause structures are less complex than corresponding subject-extracted structures. These results contrast with results from processing other Subject-Verb-Object languages like English, in which object-extracted structures are more complex than subject-extracted structures. A key word-order difference between Chinese and other Subject-Verb-Object languages is that Chinese relative clauses precede their head nouns. Because of this word order difference, the results follow from a resource-based theory of sentence complexity, according to which there is a storage cost associated with predicting syntactic heads in order to form a grammatical sentence. The results are also consistent with a theory according to which people have less difficulty processing embedded clauses whose word order matches the word order in main clauses. Some corpus analyses of Chinese texts provide results that constrain the classes of possible frequency-based theories. Critically, these results demonstrate that there is nothing intrinsically easy about extracting from subject position: depending on the word order in the main clause and in a relative clause, extraction from object position can be easier to process in some circumstances.
\end{abstract}

(C) 2003 Elsevier B.V. All rights reserved.

Keywords: Processing; Relative clauses; Chinese

\section{Introduction}

A major goal in research on human sentence processing is to discover what kinds of information people use in the moment-by-moment comprehension of a sentence. Much recent research has demonstrated that information from a variety of different sources is used, including lexical information, syntactic information, real-world knowledge, and information about the discourse context (for recent reviews, see Gibson \& Pearlmutter, 1998;

\footnotetext{
* Corresponding author. NE20-459, MIT, Cambridge, MA 02139, USA.

E-mail addresses: egibson@mit.edu (E. Gibson), fhsiao@mit.edu (F. Hsiao).
} 
Tanenhaus \& Trueswell, 1995). An important empirical observation that demonstrates the importance of the use of syntactic (word-order) information in sentence comprehension is provided by the contrast between nested structures - structures which fall between the ends of a syntactic dependency - and non-nested structures (Chomsky \& Miller, 1963; see Gibson, 1998, for a recent survey). For example, the English sentences in (1a)-(1c) are increasingly nested, and are of increasing complexity. Sentence (1d) is a right-branching (non-nested) control for (1c), and it is correspondingly much easier to understand.

(1) a. The reporter disliked the editor.

b. The reporter [that the senator attacked] disliked the editor.

c. The reporter [that the senator [that John met] attacked] disliked the editor.

d. John met the senator [that attacked the reporter] [that disliked the editor].

A relative clause $(\mathrm{RC})$ is a clause that modifies a noun, such as "that the senator attacked" or "that John met". RCs are possible in most locations, but they are very difficult to comprehend when they modify the subject of another RC in an Subject-Verb-Object (SVO) language like English, such as the modification of "the senator" by "that John met" in (1c). The complexity of (1c) cannot be explained by lexical information (e.g. word frequencies), or by the real-world plausibility of the meaning of the sentence, or by the complexity of the discourse context, because all of these factors are the same in sentence (1d), and this sentence is much less complex. As a result, the complexity of a sentence like (1c) must be due to properties of the syntax of this sentence: a complex word order. While this much is known, it remains an open question how to quantify what counts as a complex word order in the human sentence processing mechanism. The point of this paper is to restrict the range of possibilities by examining the processing of RCs in Chinese.

A second contrast between a complex and a less complex word order is the contrast between object- and subject-extracted RCs in English and other SVO languages, as in (2):

(2) a. Object-extraction: The reporter [that the senator attacked] disliked the editor.

b. Subject-extraction: The reporter [that attacked the senator] disliked the editor.

The greater complexity of object-extractions is found in a number of measures, including phoneme-monitoring, on-line lexical-decision, reading times (RTs), and response accuracy to probe questions (Ford, 1983; Hakes, Evans, \& Brannon, 1976; Holmes \& O'Regan, 1981; King \& Just, 1991; Wanner \& Maratsos, 1978; Waters, Caplan, \& Hildebrandt, 1987). Like the nesting contrast, this effect is not driven by lexical frequencies, or realworld plausibility (because this is controlled between the two structures), or discourse context. The difference must be due to a difference in the complexity of the two word orders.

There are at least five word-order factors that have been proposed that can explain these effects: ${ }^{1}$

\footnotetext{
${ }^{1}$ Note that these factors are not necessarily exclusive of one another. More than one could be in effect. In fact, Gibson $(1998,2000)$ explicitly proposes that both 1 and 2 apply together.
} 
1. Storage resources: the storage of incomplete head-dependencies in phrase structure (Chomsky \& Miller, 1963; Gibson, 1991, 1998, 2000; Lewis, 1996; Wanner \& Maratsos, 1978). These theories attribute the greater difficulty of the object-extractions to the fact that there are a larger number of temporarily incomplete dependencies in the processing of object-extractions. For example, according to the dependency locality theory (DLT; Gibson, 1998, 2000), storage resources are required to keep track of the syntactic heads that are needed to form a grammatical sentence. There is a greater storage cost in processing the object-extraction in (1a) than the subject-extraction in (1b) as soon as the first word following the wh-filler "who" is processed in each. In particular, after processing "the reporter who the" in (1a), four syntactic heads are required to form a grammatical sentence: a noun for the determiner "the", a verb for the outer clause, a verb for the inner clause, and an empty noun element associated with the wh-filler "who". In contrast, only two heads are needed after processing the word "the reporter who attacked" in (1b): a noun for the object position of "attacked" and a verb for the outer clause.

2. Integration resources: the integration of head-dependencies in phrase structure (Ford, 1983; Gibson, 1998, 2000). The process of integration consists of connecting an incoming word to its head or dependent in the current structure for the input. It has been demonstrated that the difficulty of performing an integration depends on the distance of the integration involved (Gibson, 1998; Grodner, Watson, \& Gibson, 2000; Pearlmutter \& Gibson, 2001; Warren \& Gibson, 2002). Object-extractions involve longer distance integrations than subject-extractions. In particular, the integrations at the embedded verb "attacked" in (1a) involve connecting the object position of the verb "attacked" to the whfiller "who", an integration that crosses the subject noun phrase (NP) "the senator". By contrast, the integration at the verb "attacked" in (1b) is more local, and is therefore hypothesized to consume fewer resources.

3. Differences in canonical vs. non-canonical word order (e.g. MacDonald \& Christiansen, 2002; cf. Bever, 1970; Mitchell, Cuetos, Corley, \& Brysbaert, 1995; Tabor, Juliano, \& Tanenhaus, 1997). The word order in English is SVO. This word order is present in a subject-extracted RC, e.g. who attacked the senator, such that the wh-filler "who" is the subject of the RC. In contrast, the word order in an object-extracted RC is non-canonical: OSV, e.g. who the senator attacked, hence the difficulty.

4. A theory based on accessibility of syntactic positions. This theory attributes the difference between the two extraction types to a difference in accessibility of subject- and object-extractions (Keenan \& Comrie, 1977; Keenan \& Hawkins, 1987; cf. Dowty, 1991; Hale, in press). Subject position is more accessible than object position, and the contrast follows.

5. Perspective shift (MacWhinney, 1977, 1982; MacWhinney \& Pleh, 1988; cf. Bever, 1970). Under this theory, processing resources are required to shift the perspective of a clause, where the perspective of a clause is taken from the subject of the clause. A subject-modifying object-extracted $\mathrm{RC}$ as in (1a) requires two perspective shifts: (1) from the perspective of the matrix subject to the subject of the RC; and (2) from the perspective of the subject of the RC back to the matrix subject, after the RC is processed. Processing the subject-extracted RC in (1b) requires no perspective shifts, because the matrix subject is also the subject of the RC, so that both clauses come 
from the same perspective. Thus, the object-extraction is more complex than the subject-extraction.

This paper examines on-line processing data from Chinese. Although Chinese is an SVO language, Chinese RCs precede their head nouns, unlike RCs in English and French, which follow their head noun. This difference in word order leads to different predictions among the five kinds of theories. In particular, the first three theories make different predictions from the last two theories in these constructions. Consider (3a) and (3b) below.

(3) a. Chinese object-extraction

$$
\begin{aligned}
& \text { fuhao yaoching } e_{i} \text { de guanyuan } \text { shinhuaibugui danshi shanyu yintsang } \\
& \text { tycoon invite gen official have bad intentions but good at hiding } \\
& \text { 'The official who the tycoon invited has bad intentions but is good at hiding them.' }
\end{aligned}
$$

b. Chinese subject-extraction

$$
\begin{aligned}
& e_{i} \text { yaoching fuhao de guanyuan }{ }_{i} \text { shinhuaibugui danshi shanyu yintsang } \\
& \text { invite tycoon gen official have bad intentions but good at hiding } \\
& \text { 'The official who invited the tycoon has bad intentions but is good at hiding them.' }
\end{aligned}
$$

The word $d e$ is a genitive marker in Chinese, which also serves as an RC marker. We have notated it as "gen" in the examples. For notational purposes, the empty subject and object positions are notated as empty categories, " $e$ " for short.

According to a storage-based resource theory like the DLT, the subject-extracted RC in (3b) should be more complex than the object-extracted RC in (3a), in contrast to the results from English and French. After processing the first word in the subject-extraction RC (3b) the verb yaoching ("invite") - the reader realizes that an RC is being processed, because there is no subject for the verb. ${ }^{2}$ As a result, a verb for the top-level sentence is needed, together with the RC genitive marker $d e$ and an NP object for the verb in the RC. Thus, three syntactic heads are needed at this point. After the object noun fuhao ("tycoon") is processed, two syntactic heads are still needed: the main verb and the RC genitive marker. Processing the object-extraction in (3a) requires fewer predicted heads at each of these positions. In particular, after processing the first word in the object-extraction - the noun fuhao ("tycoon") - only a single head is predicted, a verb for the clause, because this could be the main clause of the sentence. After the next word is processed - the verb yaoching ("invite") - still only one head is predicted, a noun object of the verb. When the genitive marker $d e$ is processed next in both sentences, the storage cost for each structure is the same.

\footnotetext{
${ }^{2}$ Chinese allows null pronominals in many positions, including subject position, but only in contexts where a topic is present. Null pronominals are rare and unpreferred in a null context, such as in these sentences. Thus, people are more likely to assume an RC reading rather than a null pronominal reading.
} 
An integration-based resource theory also predicts that the subject-extracted RC should be more complex than the object-extracted RC in Chinese, but the on-line location of this difficulty is predicted to be later in the sentence. In particular, although there are storage differences through the $\mathrm{RC}$, there are no integration distance differences in this region. But when the RC marker de and the head noun for the RC guanyuan ("official") are processed, integration cost differences are predicted: the integration between the pre-verbal subject position of the RC (indicated by $e i$ in (3b)) and the noun guanyuan ("official") in the subject-extraction (3b) is a longer distance than the integration between the post-verbal object position of the RC (indicated by $e i$ in (3a)) and the noun guanyuan ("official") in the object-extraction (3a).

Like the storage resource theories, the canonical word order theory predicts that the subject-extractions should be more complex than the object-extractions. The objectextracted RC sentence follows the canonical SV word order in its initial clause, before the genitive marker de is encountered. In the subject-extracted RC, a non-canonical word order is encountered initially - a verb without its subject - causing more difficult processing. Like the storage theory, this theory predicts that a processing effect will occur during the processing of the $\mathrm{RC}$.

Unlike the resource theories and the canonical word order theory, the last two theories discussed above predict that Chinese RCs should be processed like English RCs, with the result that Chinese subject-extractions should be easier to process than Chinese objectextractions. The accessibility-based theory makes this prediction independent of the word order, because subjects are more accessible and are therefore easier to extract than objects. The perspective-shift theory makes this prediction because perspective is not shifted in processing a subject-extracted RC when it modifies a subject NP as in (3b), whereas perspective is shifted when an object-extracted RC modifies a subject NP, as in (3a).

The predictions as described above do not consider potential differences between the two structures due to temporary ambiguity. One such ambiguity should be considered: the object-extracted RC is likely to be temporarily analyzed as the main clause. When the RC particle $d e$ is encountered, this analysis must be given up in favor of an RC analysis. There is no such temporary ambiguity in the subject-extraction. In particular, the subjectextracted RC is known to be an RC from the onset of the first verb, because there is no subject for this verb. As a result of this difference in temporary ambiguity across the two structures, a behavioral difference in support of the latter two theories would be difficult to interpret, because of the confounding influence of temporary ambiguity. By the same token, a behavioral difference in favor of the first three theories would be strong evidence for these theories, because such a difference would occur in spite of a potential temporary ambiguity effect in the opposite direction.

In this paper we used self-paced reading to test these predictions.

\section{Experiment}

Two pairs of conditions were tested, as exemplified in (3) above and (4) below. The RCs to be compared in (3) are singly embedded, whereas the RCs in (4) are doubly embedded. 
(4) a. Chinese doubly-embedded object-extracted RC

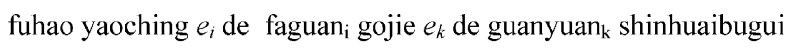

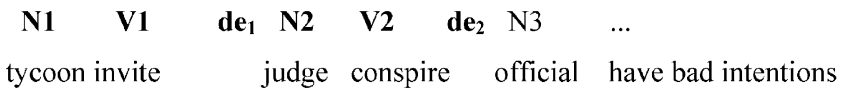

'The official who the judge who the tycoon invited conspired with has bad intentions.'

b. Chinese doubly-embedded subject-extracted RC

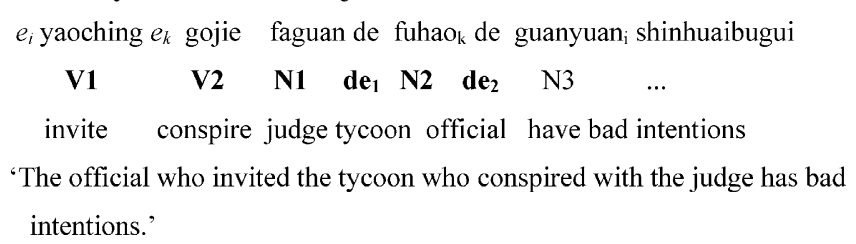

We tested doubly-embedded versions in addition to singly-embedded versions because it was possible that the predicted effects might be difficult to measure in singly-embedded versions, because of the small difference in word order between the two. The critical region of comparison in the singly-embedded versions in (3) consists of the first three words: N1 V1 de/V1 N1 de. The critical region in the doubly-embedded versions in (4) consists of the first six words: $\mathrm{N} 1 \mathrm{~V} 1 \mathrm{de}_{1} \mathrm{~N} 2 \mathrm{~V} 2 \mathrm{de}_{2} / \mathrm{V} 1 \mathrm{~V} 2 \mathrm{~N} 1 \mathrm{de}_{1} \mathrm{~N} 2 \mathrm{de}_{2}$. Each of these comparisons involves the same words in a different order, so lexical frequency is controlled overall. We controlled for plausibility using a norming study, as described below.

The predictions for the doubly-embedded structures are largely the same for each theory as for the singly-embedded structures. The accessibility and perspectivebased theories predict that the subject-extractions in (3b) and (4b) should be less complex than the object-extractions in (3a) and (4a). Resource theories make the opposite prediction: that the object-extracted RCs should be less complex than the subject-extracted $\mathrm{RCs}$. The storage theory predicts this effect during the RCs, whereas the integration theory predicts the effect later, towards the end of the RC and at the head noun in the main clause. Like the resource theories, the canonical word order theory predicts that object-extractions should be less complex than subject-extractions in the singly-embedded versions. Furthermore, the canonical word order theory predicts that object-extractions should be less complex than subject-extractions in the doubly-embedded versions, under the assumption that the word $d e$ (which usually functions as a genitive marker in Chinese) functions as an RC pronoun in an RC. ${ }^{3}$ In particular, under this assumption, the doubly-embedded object-extracted RC consists of the elements Subject-Verb-Object

\footnotetext{
${ }^{3}$ This is not necessarily the right assumption, but it gives the right processing results below. We are not aware of any existing analysis of Chinese RCs that assumes overt relative pronouns in Chinese and in particular analyzes $d e$ as a relative pronoun. As a matter of fact, Keenan (1985) conducted a cross-linguistic survey of RCs and concluded that no language with pre-nominal RCs has relative pronouns. Below we list references to analyses of Chinese RCs, none of which analyzes $d e$ as a relative pronoun: He (1996) treats de as a complementizer; Li and Thompson (1981) analyze it as a nominalizer; and Kayne (1994) treats it as an inflection marker. Refer to these papers for justifications of their analyses.
} 
Subject-Verb-Object, thus following SVO word order in each of the two RC clauses. In contrast, the doubly-embedded subject-extracted RC consists of the elements Verb-VerbObject-Subject-Object-Subject, which does not follow SVO word order in either RC.

\section{Method}

\subsection{Participants}

Forty subjects participated in the experiment. Six were from MIT and the surrounding community. Seven resided in Taiwan, and were attending a wedding in California at the time of the experiment. The other 27 were based in and around Los Angeles. All were native speakers of Mandarin Chinese spoken in Taiwan and were naive as to the purposes of the study. Furthermore, although most of the participants also spoke English, Mandarin Chinese was the primary language that they used in their day-to-day life.

\subsection{Materials}

Twenty-four sets of sentences were constructed, typed in Chinese characters, each with the four conditions in (3) and (4). The target sentences were split into four lists in a LatinSquare design. Each list was combined with 72 fillers of various types. Because all sentences were presented in a null context, none of the fillers contained any null discoursebased pronominals. Thus, it is unlikely that participants analyzed the target stimuli as containing such pronominals. Appendix A provides a complete list of the stimuli. The stimuli were pseudo-randomized separately for each participant so that at least one filler item intervened between two targets.

\subsection{Procedure}

The task was self-paced, word-by-word reading, using a moving window display (Just, Carpenter, \& Woolley, 1982). Linger 1.7 by Doug Rohde was the software used to run the experiments. All experiments were run on a single PC laptop.

Each trial began with a series of dashes marking the length and position of the words in the sentences, printed approximately a third of the way down the screen. Participants pressed the spacebar to reveal each word of the sentence. As each new word appeared, the preceding word disappeared. The amount of RT the participant spent on each word was recorded as the time between key-presses.

After the final word of each item, a yes/no comprehension question appeared which asked about information contained in the preceding sentence. Participants pressed one of two keys to respond "yes" or "no". After an incorrect answer, an equivalent sentence in Chinese meaning "Sorry, your answer was incorrect" flashed briefly on the screen. No feedback was given for correct responses. Participants were asked to read sentences at a natural rate and to be sure that they understood what they read. The comprehension questions for target items questioned the content of the main clause or one of the RCs. 
For example, two possible questions for sentence (3a) would be "Did the official invite the tycoon?" (no) or "Did the official have bad intentions?" (yes).

\section{Plausibility norming survey}

A questionnaire was conducted in order to control for potential plausibility differences between the two conditions in each pair of conditions. Thirty-three native Chinesespeaking participants from North America and Taiwan who did not take part in the selfpaced reading experiment completed the survey. Similar to the participants in the main experiment, many of these participants also spoke English, but Mandarin Chinese was the primary language that they used in their day-to-day life. The items tested in this questionnaire consisted of the simple transitive clauses that made up each RC. For the singly-embedded versions in (3), the materials consisted of one simple SVO clause in each version, as in (5). For the doubly-embedded versions in (4), there were two simple clauses for each item, as in (6) and (7).

(5) a. One clause object-extracted control: The tycoon invited the official.

b. One clause subject-extracted control: The official invited the tycoon.

(6) a. Two clause object-extracted control, verb 1: The tycoon invited the judge.

b. Two clause subject-extracted control, verb 1: The official invited the tycoon.

(7) a. Two clause object-extracted control, verb 2: The judge conspired with the official.

b. Two clause subject-extracted control, verb 2: The tycoon conspired with the judge.

Participants rated the plausibility of these sentences on a scale of 1 (natural) to 7 (unnatural). They were asked to judge the naturalness in the real world of the events described in the sentences, that is, how likely they were to occur.

The results of the survey were that four of the 24 items were found to be significantly more plausible $(P<0.05$ by $t$-test $)$ in one version. These four items were therefore omitted from the RT analyses. The remaining 20 items were matched for plausibility across all versions (means: 2.55 for (5a), 2.54 for (5b), 2.62 for (6a), 2.50 for (6b), 2.67 for (7a), and 2.65 for (7b)). The plausibility ratings for each item are presented along with the items in Appendix A.

\section{Results}

The results were analyzed using Lingalyzer 1.1, an analysis program written by Doug Rohde. The four items in which one version was less plausible than another were omitted from analyses, leaving 20 items to be analyzed. Three participants' data were omitted from the analyses because of poor comprehension question performance $(<67 \%$ accuracy 
Table 1

Mean (standard error) comprehension question performance in percent correct by condition

\begin{tabular}{llll}
\hline 1 clause object RC & 1 clause subject RC & 2 clause object RC & 2 clause subject RC \\
$75.7(3.2)$ & $70.5(3.4)$ & $75.9(3.3)$ & $64.2(3.7)$ \\
\end{tabular}

overall, as compared with a mean of $87 \%$ for the other participants). Two participants' data were omitted due to repeated interruptions during their testing sessions.

\subsection{Comprehension question performance}

The percentages of correct answers for each condition are presented in Table 1 . Although comprehension question performance was numerically better in the one-clause object-extracted sentences than in the one-clause subject-extracted sentences, this difference did not reach significance $(F \mathrm{~s}<2.1)$. In the two clause sentences, performance was better in the object-extracted versions, but this effect was fully significant only in the participants' analysis $\left(F 1(1,34)=6.35, \mathrm{MS}_{\text {within }}=0.033, P<0.05 ; F 2(1,19)=3.11\right.$, $\left.\mathrm{MS}_{\text {within }}=0.052, P=0.09\right)$. Although comprehension performance in the target items was relatively low (71.6\% overall), this was probably because (1) the subject-extracted versions were complex, and (2) the questions for these items were difficult. Mean performance on the filler items was much better at $88.7 \%$, so the participants were certainly paying attention in the task.

\section{2. $R T s$}

Because people made a substantial percentage of errors in answering the comprehension questions, we report the RT data from an analysis of all trials, independent of whether the questions were answered correctly. Analyses in which only correctly answered trials were analyzed revealed the identical patterns. In particular, there were no differences in any statistical tests whether or not the data were included. Fig. 1 plots mean RTs per word in the singly-embedded RCs in (2).

An ANOVA for the first two words (N1 V1/V1 N1) revealed that object-extractions were processed faster than subject-extractions $\left(F 1(1,34)=5.38, \mathrm{MS}_{\text {within }}=5042, P<0.05\right.$; $\left.F 2(1,19)=5.50, \mathrm{MS}_{\text {within }}=1980, P<0.05\right)$. There were no significant differences on the third word, the genitive marker $d e(F \mathrm{~s}<1)$, nor on any subsequent region.

Turning now to the doubly-embedded conditions, Fig. 2 plots mean RTs per word by region by participants. There was no significant difference at the first or second word $(F \mathrm{~s}<1.9)$. We did not compare RTs at the third word by itself because this word was the high frequency, short function word $d e$ in the object-extraction condition, whereas the same position was a noun in the subject-extraction condition. The same issue was present at the fourth word, which was the function word $d e$ in the subject-extraction condition, but a noun in the object-extraction condition. As a result, we collapsed the third and fourth words together as a single region for comparisons. This way the region contained the same words across the two conditions, but in a different order. An ANOVA on this region revealed that object-extractions were processed faster than subject-extractions 


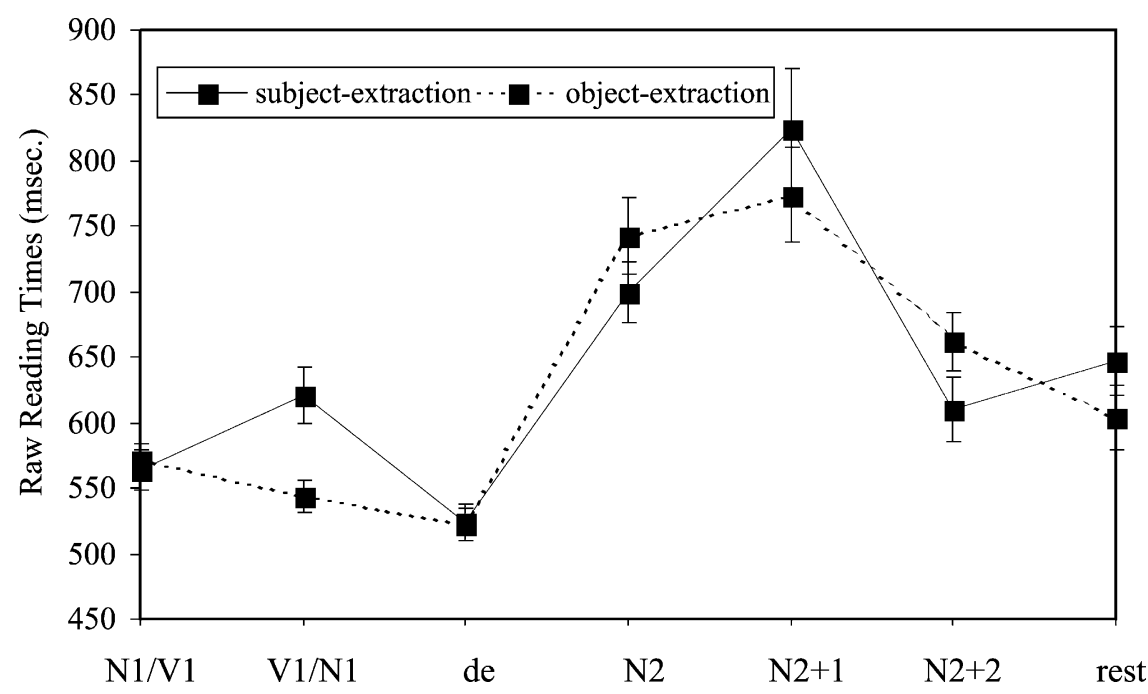

Fig. 1. Plot of mean (standard error) raw RTs per word for the singly-embedded conditions in (2).

$\left(F 1(1,34)=24.2, \mathrm{MS}_{\text {within }}=20114, P<0.001 ; F 2(1,19)=23.4, \mathrm{MS}_{\text {within }}=10917\right.$, $P<0.001)$. At each of the fifth and sixth words, an ANOVA revealed similar effects (word 5: $\quad F 1(1,34)=9.0, \quad \mathrm{MS}_{\text {within }}=76964, \quad P=0.005 ; \quad F 2(1,19)=4.3$, $\mathrm{MS}_{\text {within }}=90848, P=0.05$; word 6: $F 1(1,34)=11.1, \mathrm{MS}_{\text {within }}=278539, P<0.005$; $\left.F 2(1,19)=22.7, \mathrm{MS}_{\text {within }}=57551, P=0.001\right)$. Over the first six words taken as a whole, object-extractions were read faster than subject-extractions $(F 1(1,34)=27.3$, $\left.\mathrm{MS}_{\mathrm{within}}=15088, P<0.001 ; F 2(1,19)=43.5, \mathrm{MS}_{\mathrm{within}}=4905, P<0.001\right)$.

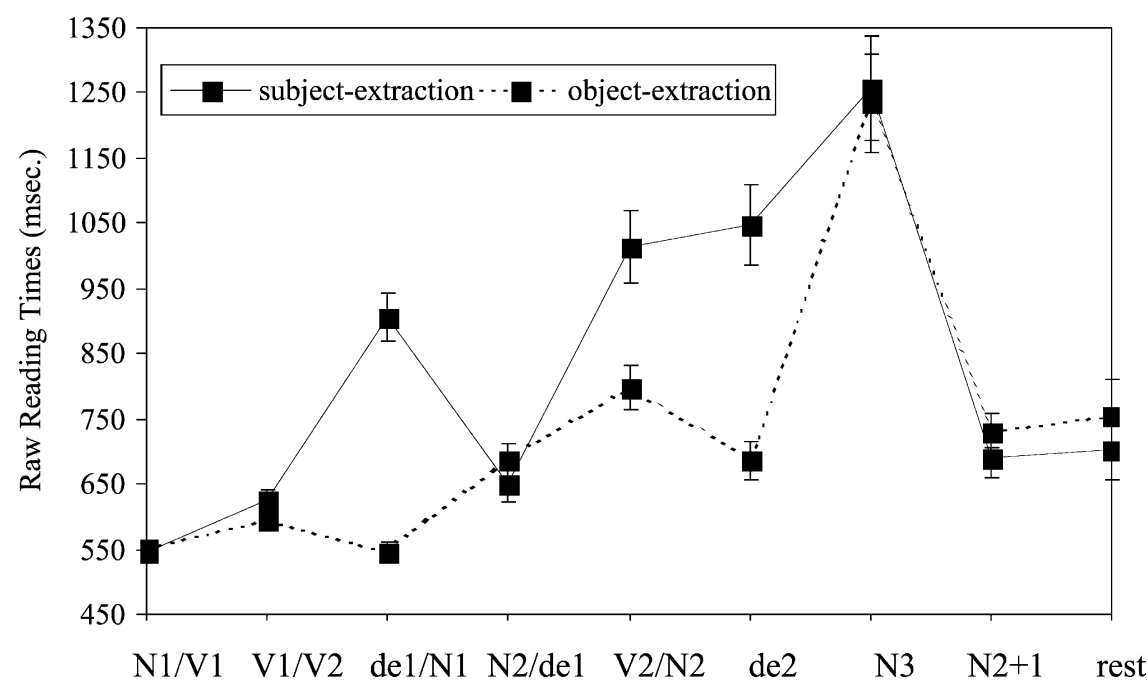

Fig. 2. Plot of mean (standard error) raw RTs per word for the doubly-embedded conditions in (3). 


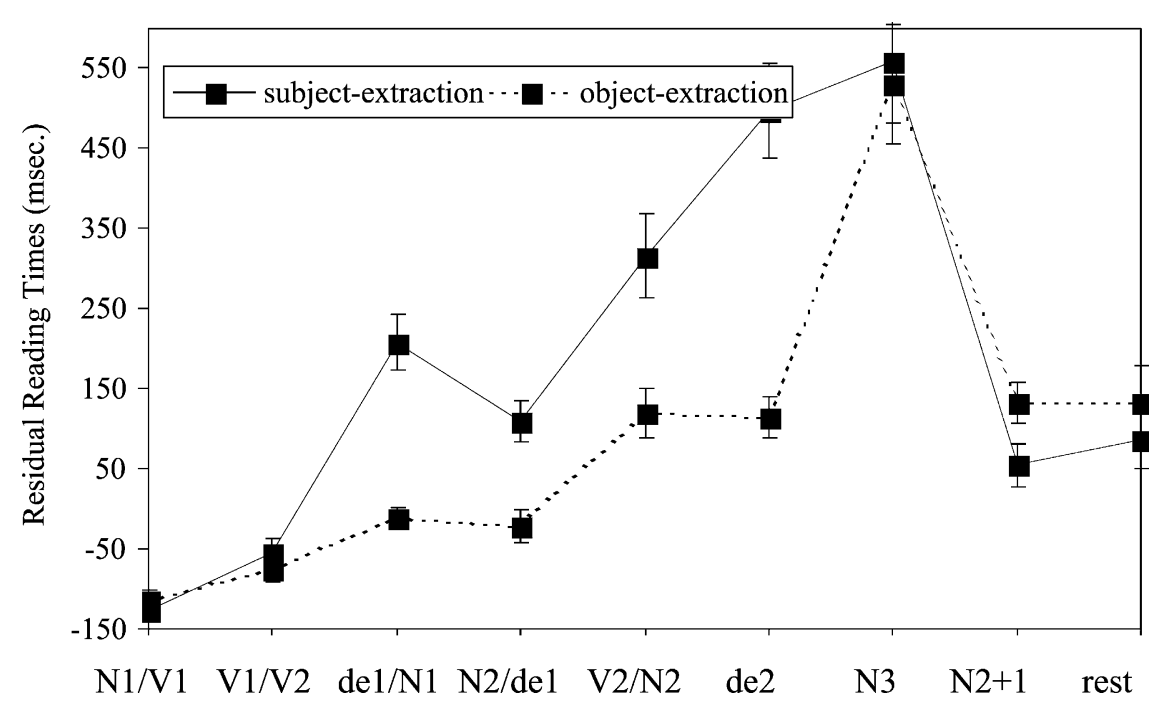

Fig. 3. Plot of mean (standard error) residual RTs per word for the doubly-embedded conditions in (3).

Because the content of the regions being compared in the doubly-embedded conditions differed substantially at certain word positions (e.g. the genitive marked de is compared with a noun at the third word position), we also conducted an analysis of RTs that were adjusted for differences in word length. In order to do this, a regression equation predicting RT from word length was constructed for each participant, using all filler and experimental items (Ferreira \& Clifton, 1986; see Trueswell, Tanenhaus, \& Garnsey, 1994, for discussion). At each word position, the RT predicted by the participant's regression equation was subtracted from the actual measured RT to obtain a residual RT. Mean wordby-word residual RTs computed across participants are plotted in Fig. 3.

The results were similar for the analyses of residual RTs. An ANOVA in the first two words revealed no significant effects $(F \mathrm{~s}<1.2)$. The subject-extractions were read more slowly over positions three and four $\left(F 1(1,34)=30.2, \mathrm{MS}_{\text {within }}=18630, P<0.001\right.$; $\left.F 2(1,19)=26.1, \mathrm{MS}_{\text {within }}=11131, P<0.001\right)$. At each of the fifth and sixth words, an ANOVA revealed similar effects (word 5: $F 1(1,34)=8.2, \mathrm{MS}_{\text {within }}=75545, P<0.01$; $F 2(1,19)=5.2, \quad \mathrm{MS}_{\text {within }}=67624, \quad P<0.05 ; \quad$ word $\quad 6: \quad F 1(1,34)=12.1$, $\left.\mathrm{MS}_{\text {within }}=269862, P=0.001 ; F 2(1,19)=32.4, \mathrm{MS}_{\text {within }}=45371, P<0.001\right)$. Over the first six words taken as a whole, object-extractions were read faster than subjectextractions $\quad\left(F 1(1,34)=30.4, \quad \mathrm{MS}_{\text {within }}=14114, \quad P<0.001 ; \quad F 2(1,19)=78.5\right.$, $\left.\mathrm{MS}_{\text {within }}=2926, P<0.001\right)$.

\section{Discussion}

The evidence that was gathered here demonstrates that subject-extracted RCs are more complex than object-extracted RCs in Chinese, contrary to the results in the literature for the same construction in other languages. The reaction time data in comparisons involving 
both singly- and doubly-embedded conditions provided the strongest evidence for this observation, with the response accuracy data providing some additional support.

These results are as predicted by storage-based resource theories and the canonical word order theory, but they clearly contradict the predictions of the accessibility theory and the perspective-shift theory. The predictions of the integration-based theory were also not ratified. Critically, these results demonstrate that there is nothing intrinsically easy about extracting from subject position: depending on the word order in the main clause and in a RC, extraction from object position can be easier to process in some circumstances. We discuss the resource theories and the canonical-word-order theory in turn below.

First, consider the storage-based resource theory, in particular the on-line storage theory proposed by Gibson $(1998,2000)$, in which there is a storage cost associated with predicting syntactic heads. This theory correctly predicts the contrast between subject- and object-extractions in both singly- and doubly-embedded structures. Furthermore, this theory correctly predicts the locus of the effect, during the processing of each RC. Not all storage-based resource theories can explain these results. In particular, the theory of Lewis (1996) proposes that there is interference cost associated with maintaining multiple incomplete phrase-structure dependencies only when they are the same kind of syntactic dependency. In particular, incomplete subject-verb dependencies interfere with one another, but not with other incomplete dependencies. Although this theory can account for the results of the comparisons involving the doubly-embedded structures, it does not account for the results of the comparisons involving the singly-embedded structures. In particular, there is at most one incomplete dependency of any single type during the processing of the singly-embedded subject-extracted $\mathrm{RC}$, the same as during the processing of the object-extracted RC. Thus, a storage cost theory based on predicted heads in which different kinds of predictions cause additive difficulty fares better on the singly-embedded structures than a theory in which interference cost only accumulates when multiple incomplete dependencies of the same kind are present.

The integration-distance resource theory correctly predicted that object-extractions should be less complex than subject-extractions in Chinese, but the locus of this effect was not correctly predicted, especially in the singly-embedded structures. In particular, the integration-distance theory predicts no differences during the processing of the RC, and it predicts a difference at the head noun, the point at which people are connecting the positions in the RC to the head noun. But no difference was observed in this region, contrary to prediction. The processing difference that was observed during the RC is more consistent with the prediction of the storage-based resource theory.

The second theory that can successfully account for the results presented here is the canonical word order theory. Under the assumption that the word de serves as an RC pronoun, this theory correctly predicts that object-extracted RCs should be processed more easily than subject-extracted RCs in Chinese, for both singly- and doubly-embedded constructions (but see footnote 3 for some alternative analyses of $d e$ from the syntax literature). It remains an open question how to formalize this theory so that it makes more detailed predictions. One version of this kind of theory is a frequency-based theory, such that people have less difficulty with word orders that they encounter more frequently: the canonical word orders. If stated purely in terms of tabulating frequencies of input (e.g. the tuning theory of Mitchell et al., 1995), such a comprehension theory makes no prediction 
about what kinds of word orders could serve as canonical, or about what kinds of attachment preferences people might have when faced with ambiguity: any word order could serve as canonical, and any structure may be preferred over any other in the face of ambiguity (see Desmet \& Gibson, in press; Gibson \& Schutze, 1999, for further discussion of such theories). ${ }^{4}$ Alternatively, a canonical-word-order comprehension theory may be driven in part by architectural limitations, which may constrain the processability of different word orders and attachment preferences. Connectionist systems provide examples of this kind of model (e.g. Christiansen \& Chater, 1999; Rohde, 2002; Tabor et al., 1997). The architecture of such a system may then give rise to a resource theory, such as the storage- or integrationbased theories discussed above (Gibson, 1998). Because some versions of a canonical word order theory consist of different levels of analysis of resource theories, it may be impossible to provide evidence that demonstrates that one theory is correct and the other is wrong. Rather, aspects of both may turn out to be correct. Relatedly, these kinds of theories make the same predictions with respect to many phenomena, including the behavioral data discussed here. Specifically, the current results do not provide evidence relevant to distinguishing the canonical-word-order theory from resource-based theories.

One prediction of a frequency-based canonical word order theory that is worthy of discussion is that there should be a correlation between (1) structural frequencies in corpora and (2) behavioral measures such as RTs. But because no current frequencybased theory makes a specific hypothesis of what granularity of structures is being tabulated, it is difficult to quantify exactly what one of these theories predict for any given structural comparison. One potential frequency-based theory is one in which RC frequencies are tabulated independent of main clause structures. Such a theory is consistent with the spirit of the tuning hypothesis of Mitchell et al. (1995). Under such a theory, Chinese object-extracted RCs should be more frequent in the input than corresponding subject-extracted RCs, because object-extracted RCs are easier to comprehend. In order to test this hypothesis, we analyzed the Chinese Treebank, version 3.0, published by the Linguistic Data Consortium. The Chinese Treebank is a parsed corpus consisting of approximately 100,000 words that were taken from the Xinhua newswire between 1994 and 1998. All instances of RCs from this corpus were initially examined, but we restricted our counts to RCs that matched the target RCs in the experiment at a broad level. In particular, we examined only active RCs (omitting passives) and instances of argument relativization (omitting adjunct relativizations such as the reason why he left). We also did not count simple phrases that lacked copula verbs that could be analyzed as reduced subject-extracted RCs, e.g. prepositional phrases such as 'The company in China' cf. 'The company that is in China', or adjectival phrases such as 'The big company' vs. 'The company that is big'. We thought that the inclusion of such items could artificially increase the number of subject-extracted RCs. In total, 882 instances were found in the corpus, $375(42.5 \%)$ of which were object-extracted RCs. The remaining 507 (57.5\%) instances were subject-extracted RCs. Interestingly, subject-extracted RCs are more frequent, despite being harder to comprehend. This result therefore disconfirms

\footnotetext{
${ }^{4}$ It is possible that there are no such constraints on comprehension, but that a theory of production constrains the kinds of word orders and ambiguity preferences that are produced (MacDonald, 1999).
} 
a version of the tuning hypothesis, one in which structural frequencies are tabulated at this level of granularity.

We performed a second narrowed-down search of these 882 instances that matched the experimental items more closely. The RCs included in the first analysis were heterogeneous, and generally had many properties that distinguished them from the experimental items. For example, the verbs in the corpus RCs could be either transitive or intransitive, and the subjects and objects of the RCs consisted of various kinds of NPs: (definite, indefinite, animate, inanimate, human, non-human, pronouns, proper names, empty categories such as pro), etc. We thus conducted a fine-grained search of the RCs for items that matched the experimental items such that they all included transitive verbs, definite human subjects and definite human objects. There were only six instances of RCs matching this description, all of which were subject-extracted RCs in the subject position of a sentence. Thus, we see no support for a tuning hypothesis at this extremely fine grain of corpus frequency matching either.

The results of the current RT study are interesting for two additional reasons. First, the benefit for object-extracted RCs over subject-extracted RCs occurred in spite of the fact that there is a potential temporary ambiguity in the object-extraction, but not in the subject-extraction. These results therefore provide an important data point in formalizing theories of sentence reanalysis (see e.g. Fodor \& Ferreira, 1998; Grodner, Gibson, Argaman, \& Babyonyshev, in press; Sturt, Pickering, \& Crocker, 1999). In particular, the lack of difficulty associated with this ambiguity suggests that a main clause structure for the initial string of the object-extracted RC is probably used in the construction of the RC structure. This is possible because no restructuring in thematic role assignments is needed in the switch from main clause to embedded clause. Furthermore, the phrase structure associated with a main clause analysis of an initial Subject-Verb sequence is the same phrase structure as is present in a RC.

Second, these results also provide evidence relevant to the syntactic representation of Chinese RCs. In particular, the fact that object-extracted RCs incur more processing difficulty than subject-extracted RCs in Chinese makes an analysis unlikely in which there is an empty wh-pronoun on the left of the RC, mediating the head noun for the RC to the right and the empty position inside the RC. Such an analysis would make the structure of RCs more similar across languages, but is not compatible with the current data. If there were such a position, and integrations to it incurred processing cost (as they do in English), then there would be no processing advantage for object-extractions over subject-extractions in Chinese. The fact that there is such an advantage makes it likely that there is no empty wh-pronoun initiating Chinese RCs.

\section{Acknowledgements}

We would like to thank the following people for their comments on earlier drafts of this work: Alec Marantz, David Pesetsky, Doug Rohde, the audience at the CUNY 2003 
sentence processing conference, and three anonymous reviewers. We would especially like to thank Doug Rohde for his help in setting up the software to run and analyze the experiment. This work is a component of the first author's PhD thesis, Hsiao (2003).

\section{Appendix A. Experimental items}

1.

a. 助教質疑的學生很不高興所以四處投訴 (2.18)

zhujiao zhiyi $e_{i}$ de xuesheng, hen bugaoxing suoyi sichu tousu

TA question student very unhappy thus everywhere complain

'The student who the TA has doubts about is very unhappy and thus complains to everyone.'

b. 質疑助教的學生很不高興所以叫處投挀 (2.61)

$e_{1}$ zhiyi zhujiao de xuesheng, hen bugoaxing suoyi sichu tousu

question TA student very unhappy thus everywhere complain

'The student who has doubts about the TA is very unhappy and thus complains to everyone.'

c. 助教質疑的教授輔導的學生很不高興 (3.39) (1.79)

zhujiao zhiyi $e_{i}$ de jiaoshou ${ }_{i}$ fudao $e_{k}$ de xuesheng $_{k}$ hen bugaoxing

TA question professor advise student very unhappy

'The student who the professor who the TA has doubts about advises is very unhappy.'

d. 䫓疑輔導助教的教授的學生很不高興 (2.58) (2.18)

$e_{i}$ zhiyi $e_{k}$ fudao zhujiao de jiaoshou ${ }_{k}$ de $x_{\text {uesheng }}$ hen bugaoxing

question advise TA professor student very unhappy

'The student who has doubts about the professor who advises the TA is very unhappy.'

2.

a. 老闆信任的工程師工作很認真效率又高 (2.09)

laoben $x$ inren $e_{i}$ de gongchengsh $i_{i}$ gongzuo hen renzhen xiaolu you gao

boss trust engineer work very hard efficiency also high

'The engineer who the boss trusts works very hard and is also very efficient.'

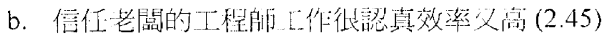

$e_{i}$ xinren laoben de gongchengshi, gongzuo hen renzhen xiaolu you gao trust boss engineer work very hard efficiency also high

'The engineer who trusts the boss works very hard and is atso very efficient.'

c. 老闆信仜的秘書喜歡的工程㸝工作很認真 (2.12) (2.64)

laoben xinren $\mathrm{e}_{i}$ de mishu $_{i}$ xihuan $\mathrm{e}_{k}$ de gongchengshi ${ }_{k}$ gongzuo hen renzhen

boss trust secretary like engineer work very hard

'The engineer who the secretary who the boss trusts likes works very hard.'

d. 信仜喜歡秘書的老闆的工程所工作胙裙真 (2.45) (2.33)

$e_{1}$ xinren $e_{k}$ xihuan mishu de laoben ${ }_{k}$ de gongchengshi, gongzuo hen renzhen trust like secertary boss engineer work very hard

'The engineer who trusts the boss who likes the secretary works very hard.' 
3.

a. 教授認識的作家很有名著作也很多 (2.24)

jiaoshou renshi $e_{i}$ de zuojia henyouming zhuzuo ye henduo professor know writer very famous works also very many 'The writer who the professor knows is very famous and has written many works (books).'

b. 認識教授的作家很有名著作也很多 (2.12)

$e_{i}$ renshi jiaoshou de zuojia henyouming zhuzuo ye henduo know professor writer very famous works also very many 'The writer who knows the professor is very famous and has written many works (books).

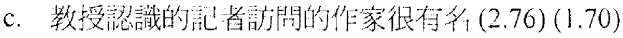

jiaoshou renshi $e_{i}$ de jizhe, fangwen $e_{k}$ de zuojiak henyouming professor know reporter interview writer very famous

'The writer who the reporter who the professor knows interviewed is very famous.'

d. 認識訪開教授的記者的作家很有舀 (2.39) (2.12)

$\mathrm{e}_{\mathrm{i}}$ renshi $\mathrm{e}_{\mathrm{k}}$ fangwen jiaoshou de jizhe $\mathrm{e}_{\mathrm{k}}$ de zuojia

know interview professor reporter writer very famous

'The writer who knows the reporter who interviewed the professor is very famous.'

4.

a. 聲樂家潜美的指揮家很有天份但是也很驕傲 (2.06)

hengyuejia zanmei $e_{i}$ de zhihuejia hen you tienfen danshi ye hen jiaoao opera singer praise conductor very have talents but also very prideful

'The conductor who the opera singer praised is very talented but is also very prideful.'

b. 潜美馨樂家的指揮家很有天份但是也很䣖傲 (2.03)

$\mathrm{e}_{1}$ zanmei shengyuejia de zhihuejia, hen you tienfen danshi ye hen jiaoao praise opera singer conductor very have talents but also very prideful 'The conductor who praised the opera singer is very talented but is also very prideful.'

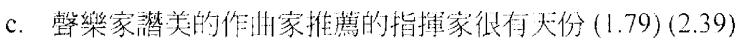

shengyuejia zanmei $e_{i}$ de zuoqujia tuijian $e_{k}$ de zhihuejia hen you tienfen opera singer praise composer recommend conductor very have talents 'The conductor who the composer who the opera singer praised recommended is very talented.'

d. 僣美推薦作曲家的馨樂家的指揮家很府天份 (2.03) (2.15)

$e_{1}$ zanmei $e_{k}$ tuijian zuoqujia de shengyuejia ${ }_{k}$ de zhihuejia hen you tienfen praise recommend composer opera singer conductor very have talents 'The conductor who praised the opera singer who recommended the composer is very talented.'

5 .

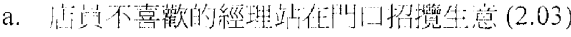

dianyuan buxihuan $e_{\text {, de }}$ jingli zhan zai dianmenkou zhaolan shengyi clerk dislike manager stand store entrance try to attract business 'The manager who the clerk dislikes is standing by the store entrance.'

b. 不喜灌店只的經理站在閒口招攬生意 $(2.33)$

$e_{i}$ buxihuan dianyuan de jingli; zhan zai dianmenkou zhaolan shengyi dislike clerk manager stand store entrance try to attract business 'The manager who dislikes the clerk is standing by the store entrance.' 
c. 店员不喜歡的顧客認識的經理站在鬥1 (2.55) (2.15)

dianyuan buxihuan $e_{i}$ de guke, renshi $e_{k}$ de jingli $i_{k}$ zhan zai dianmenkou clerk dislike customer know manager stand store entrance 'The manager who the customer who the clerk dislikes knows is standing by the store entrance.'

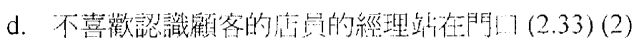

e, buxihuan $e_{k}$ renshi guke de dianyuan $n_{k}$ de jingli zhan zai dianmenkou dislike know customer clerk manager stand store entrance 'The manager who dislikes the clerk who knows the customer is standing by the store entrance.'

6.

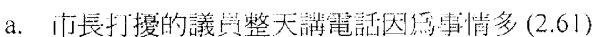

shichang daorao $e_{i}$ de yiyuan, zhengtian jiang dianhua yinwei shiching duo mayor disturb senator talk on the phone all day because things many 'The senator who the mayor disturbed talks on the phone all day because there are many things to do.'

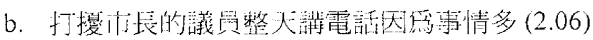

$\mathrm{e}_{\mathrm{i}}$ daorao shichang de yiyuan; zhengtian jiang dianhua yinwei shiching duo disturb mayor senator talk on the phone all day because things many 'The senator who disturbed the mayor talks on the phone all day because there are many things to do.'

c. 市長打啰的律師辩謢的議员整天亚電話 $(2.91)(2.21)$

shichang daorao $e_{i}$ de lushi, bianhu $e_{k}$ de yiyuan ${ }_{k}$ zhengtian jiang dianhua mayor disturb lawyer defend senator talk on the phone all day - The senator who the lawyer who the mayor disturbed defends talks on the phone all day.'

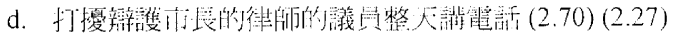

$e_{1}$ daorao $e_{k}$ bianhu shichang de lyshi $i_{k}$ yiyuan; zhengtian jiang dianhua disturb defend mayor lawyer senator talk on the phone all day 'The senator who disturbed the lawyer who defends the mayor talks on the phone all day.'

7.

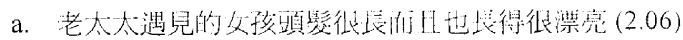

laotaitai yujian $e_{1}$ de nuhai, toufa hen chang erqie ye chang de hen piaoliang old lady meet girl hair very long and also look very beautiful 'The girl who the old lady met has very long hair and is also very beautiful.'

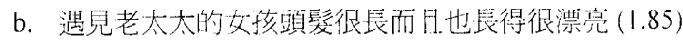

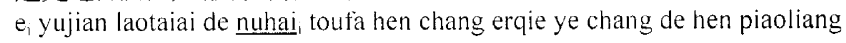
meet old lady girl hair very long and also look very beautiful

'The girl who met the old lady has very long hair and is also very beautiful.'

c. 老太太遇兒的运報童假裝沒看見的女孩頭髮很辰 (2.09) (3.03)

laotaitai yujian $e_{i}$ de songbaotong jiazhung meikanjian $e_{k}$ de nuhai ${ }_{k}$ toufa hen chang old lady meet newspaper boy pretend not to see girl hair very long -The girl who the newspaper boy who the old lady met pretends not to see has very long hair.' 


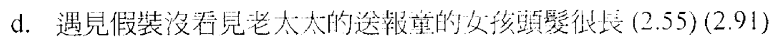

$e_{i} y u j i a n e_{k}$ jiazhung meikanjian laotaiai de songbaotong de nuhai, toufa hen chang meet pretend not to see old lady newspaper boy girl hair very long 'The girl who met the newspaper boy who pretends not to see the old lady has very long hair.'

8.

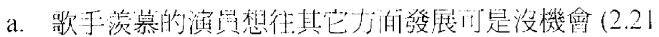

geshou xianmu $e_{i}$ de yanyuan $x$ xiang wang quta fangmian fazhan keshi mei jihuei singer envy actor want to explore other areas but no opportunity 'The actor who the singer envies wants to explore other areas but hasn't had opportunities (to do so).'

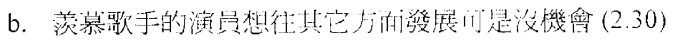

$e_{1} x i a n m u$ geshou de yanyuan, xiang wang quta fangmian fazhan keshi mei jihuei envy singer actor want to explore other areas but no opportunity 'The actor who envies the singer wants to explore other areas but hasn't had opportunities (to do so).'

c. 歌手荻慕的漞播提拔的演只想往其它方面弡展 (2.45) (1.64)

geshou xianmu $e_{i}$ de daobo, tiba $e_{k}$ de yanyuan ${ }_{k}$ xiang wang quta fangmian fazhan singer envy producer promote actor want to explore other areas 'The actor who the producer who the singer envies promoted wants to explore other areas.'

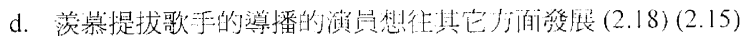

$e_{1}$ xianmu $e_{k}$ tiba geshou de daobo $o_{k}$ de yanyuan, xiang wang quta fangmian fazhan envy promote singer producer actor want to explore other areas 'The actor who envies the producer who promoted the singer wants to explore other areas.'

9.

a. 大们拜訪的粼诂家境不好常需琶朋发䛾忙 (2.58)

dabo baifang $e_{i}$ de $\varliminf_{\text {inju }}$ jiajing bu hao chang xuiyao pengyou bangmang uncle visit neighbor financially not in a good condition often need friend help 'The neighbor' who (my) uncle visited is financially not in a good condition and often needs friends to help them.'

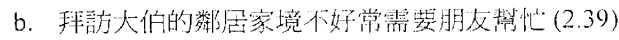

e, baifang dabo de linju, jiajing bu hao chang xuiyao pengyou bangmang

visit uncle neighbor financially not in a good condition often need friend help

- The neighbor who visited (my) uncle is financially not in a good condition and often needs friends to help them.'

c. 大约拜訪的老人家不理會的鄰居家境不好 (2.55) (3)

dabo baifang $e_{i}$ de laorenchia bulihue $e_{k}$ de $\underline{\text { linju }}_{k}$ jiajing bu hao uncle visit old person ignore neighbor financially not in a good condition 'The neighbor who the old person who (my) uncle visited ignores is financially not in a good condition.

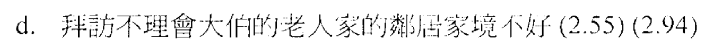

$e_{i}$ baifang $e_{k}$ bulihue dabo de laorenchia ${ }_{k}$ de $\underline{l i n j}_{i}$ jiajing bu hao visit ignore uncle old person neighbor financially not in a good condition "The neighbor who visited the old person who ignores (my) uncle is financially not in a good condition.' 
10.

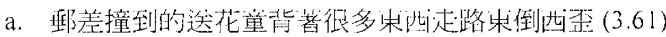

youchai zhuangdao $\mathrm{e}_{i}$ de songhuatong, beizhe hen duo dongsi zoulu dongdaoxiwai mailman collide into flower boy carry a lot of stuff walk not in a straight line 'The flower boy who the mailman collided into was carrying a lot of stuff and was not walking in a straight line.'

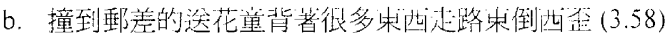

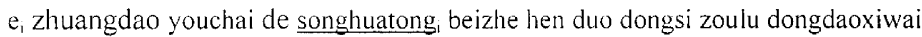
collide into mailman flower boy carry a lot of stuff walk not in a straight line 'The flower boy who collided into the mail man was carrying a lot of stuff and was not walking in a straight line.'

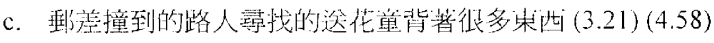

youchai zhuangdao $e_{i}$ de luren $x_{i}$ xunchao $e_{k}$ de songhuatong ${ }_{k}$ beizhe hen duo dongsi mailman collide into pedestrian look for flower boy carry a lot of stuff 'The flower boy who the pedestrian who the postman collided into was looking for was carrying a lot of stuff."

d. 撞到塞战郵差的路人的送花童背著很多林四 (3.15) (3.76)

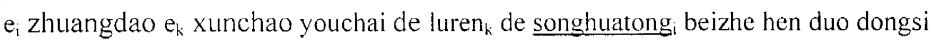
collide into look for mailman pedestrian flower boy carry a lot of stuff 'The flower boy who collided into the pedestrian who was looking for the mail man was carrying a lot of stuff.'

11.

a. 私家偵探跟蹤的警探想畑道其相所以很積㢦 (3.33)

sijiazhentan genzong $e_{i}$ de jingtan $_{i}$ xiang zhidao zhenxiang suoyi hen jiji private detective follow detective want to know the truth thus very aggressive 'The police detective who the private detective followed wants to know the truth and is thus very aggressive.'

b. 跟蹤私家偵探的警探想知道真相所以很積枸 (3)

$e_{i}$ genzong sijiazhentan de jingtan, xiang zhidao zhenxiang suoyi hen jiji follow private detective detective want to know the truth thus very aggressive 'The police detective who followed the private detective wants to know the truth and is thus very aggressive.'

c. 私家傎探跟蹤的線民畏整的警探想知道真相 (2.48) (2.64)

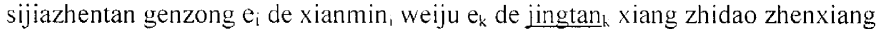
private detective follow informer fear detective want to know the truth 'The police detective who the informer who the private detec tor followed feared wants to know the truth.'

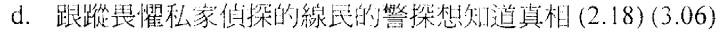

$e_{i}$ genzong $e_{k}$ weiju sijiazhentan de xianmin $_{k}$ de jingtan ${ }_{i}$ xiang zhidao zhenxiang follow fear private detective informer detective want to know the truth 'The police detective who followed the informer who fears the private detective wants to know the truth.' 
12.

a. 小开㷬仿的喜劇演員很受群䈋歡迎常被要求簽平 (2.03)

xiaochou mofang $e_{i}$ de xijuyanyuan, hen shou qunchong huanying chang bei yaoqiu qianming

clown imitate comedian be very popular with the public often passive ask

autograph

'The comedian who the clown imitates is very popular with the public and is often asked to autograph.

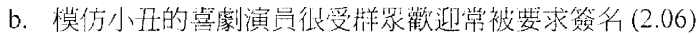

$e_{i}$ mofang xiaochou de xijuyanyuan, hen shou qunchong huanying chang bei yaogiu qianming

imitate clown comedian be very popular with the public often passive ask autograph

'The comedian who imitates the clown is very popular with the public and is often asked to autograph.

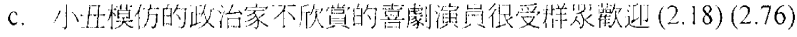

xiaochou mofang $e_{i}$ de chengchijia, buxinshang $e_{k}$ de xijuyanyuan ${ }_{k}$ hen shou qunchong huanying

clown imitate politician not like comedian be very popular with the public

'The comedian who the politician who the clown imitates does not like is very popular with the public.'

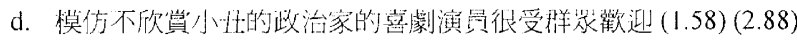

$e_{i}$ mofang $e_{k}$ buxinshang xiaochou de chengchijia $a_{k}$ de xijuyanyuan, hen shou qunchong huanying

imitate not like clown politician comedian be very popular with the

public

'The comedian who imitates the politician who does not like the clown is very popular with the public.'

13.

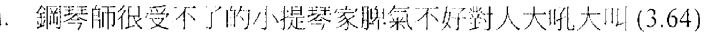

gangchinshi hen shoubuliao $e_{i}$ de xiaotichiniia, pichi buhao duiren dahodajia

pianist cannot stand violinist have a bad temper to people yell loudly

'The violinist who the pianist cannot stand has a bad temper and yells loudly at people.'

b. 很受不了鋼琴所的小提琴家脾氣不好對人大吼大叫 (3.70)

$\mathrm{e}_{i}$ hen shoubuliao gangchinshi de xiaotichinjia pichi buhao duiren dahodajia

cannot stand pianist violinist have a bad temper to people yell loudly

'The violinist who cannot stand the pianist has a bad temper and yells loudly at people.'

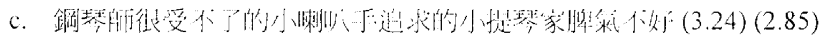

gangchinshi hen shoubuliao $e_{1}$ de xiaolabashou, zhuiqui $e_{k}$ de xiaotichinjia

pianist cannot stand trumpeter court violinist have a bad

temper

'The violinist who the trumpeter who the pianist cannot stand is courting has a bad temper.'

d. 很受不了追求鋼琴師的小喇入手的小提琴家脾氣不好 (3.33) (2.82)

$e_{i}$ hen shoubuliao $e_{k}$ zhuiqui gangchinshi de xiaolabashou $u_{k}$ de xiaotichinjia cannot stand court pianist trumpeter violinist have abad temper 
14.

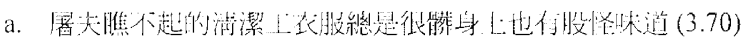

tufu chiabuchi $e_{i}$ de chingjiegong yifu zongshi hen zang shenshang ye you gu guaiweidao butcher despise cleaning person clothes always very dirty have also smell funny

"The cleaning person who the butcher despises, his clothes are always very dirty and he also smells funny.

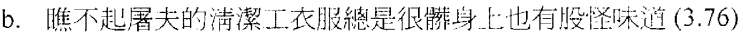

$e_{1}$ chiabuchi tufu de chingjiegong ${ }_{i}$ yifu zongshi hen zang shenshang ye you gu guaiweidao despise butcher cleaning person clothes always very dirty have also smell funny 'The cleaning person who despises the butcher, his clothes are always very dirty and he also smells funny.

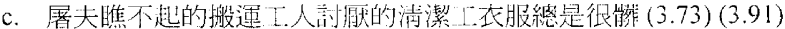

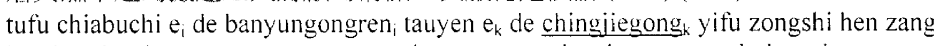
butcher despise mover detest cleaning person clothes always very

dirty

'The cleaning person who the mover who the butcher despises, his clothes are always very dirty.'

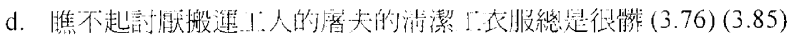

$e_{1}$ chiabuchi $e_{k}$ tauyen banyungongren de tufu $\mathrm{u}_{k}$ de chingjiegong, yifu zongshi hen zang despise detest mover butcher cleaning person clothes always very dirty

'The cleaning person who despises the butcher who detests the mover, his clothes are always very dirty.'

15.

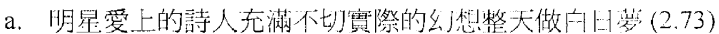

mingshing aishang $e_{1}$ de $\underline{s h i r e n}_{i}$ chongman buq̣ieshiji de huanshiang zhangtian zuo bairimong

superstar fall in love with poet have unrealistic expectations all day daydream

'The poet who the superstar fell in love with has unrealistic expectations and daydreams all the time.'

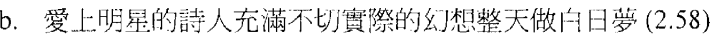

$\mathrm{e}_{i}$ aishang mingshing de shiren ${ }_{i}$ chongman buqieshiji de huanshiang zhangtian zuo bairimong

fall in love with superstar poet have unrealistic expectations all day daydream 'The poet who fell in love with the superstar has unrealistic expectations and daydreams all the time.

c. 明星愛上的模特兒崇拜的詩人充滿什切實際的乡想 (2.18) (2.88)

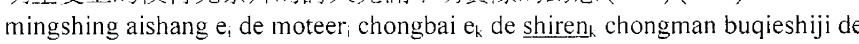
huanshiang

superstar fall in love with model adore poet have unrealistic expectations 'The poet who the model who the superstar fell in love with adores has unrealistic expectations.'

d. 愛上崇拜明星的慔特兒的詩人充淽不切實際的公想 (2.58) (2.24)

$e_{i}$ aishang $e_{k}$ chongbai mingshing de moteer $_{k}$ de shiren, chongman buqieshiji de huanshiang

fall in love with adore superstar model poet have unrealistic expectations 'The poet who fell in love with the model who adores the superstar has unrealistic expectations.' 
16.

a. 寡婦嘲笑的老處女很想交另朋友整天要人幫她作媒 (3.48)

guafu chaoshiao $\mathrm{e}_{\mathrm{i}}$ de laochunu $\mathrm{u}_{\mathrm{i}}$ henshiang jiao nanpengyou zhengtian yaoren bang ta zuo mei

widow laugh at spinster desire to have a boyfriend all day want people help her match making

'The spinster who the widow laughts at desires to have a boyfriend and wants people to set her up with someone all the time.:

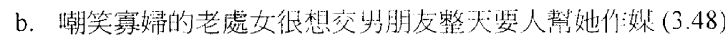

$\mathrm{e}_{\mathrm{i}}$ chaoshiao guafu de laochunu, henshiang jiao nanpengyou zhengtian yaoren bang ta zuo mei

laught at widow spinster desire to have a boyfriend all day want people help her match making

'The spinster who laughs at the widow desires to have a boyfriend and wants people to set her up with someone all the time.'

c. 賽媂嘲笑的無赖喜歡調戲的老處女很想交男朋友 (3.24) (2.48)

guafu chaoshiao $\mathrm{e}_{\mathrm{i}}$ de wulai $\mathrm{x}_{\mathrm{i}}$ ihuan tiaosi $\mathrm{e}_{\mathrm{k}}$ de $\underline{\text { laochunu}}_{\mathrm{k}}$ henshiang jiao nanpengyou widow laugh at rotter like to flirt with spinster desire to have a boyfriend - The spinster who the rotter who the widow laughts at likes to flirt with desires to have a boyfriend.'

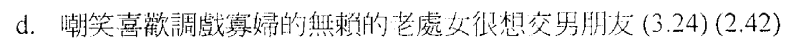

$e_{i}$ chaoshiao $e_{k} x$ ihuan tiaosi guafu de wula $i_{k}$ de laochunu, henshiang jiao nanpengyou laught at like to flirt with widow rotter spinster desire to have a boyfriend 'The spinster who laughs at the rotter who likes to flirt with the widow desires to have a boyfriend.'

17.

a. 流纸威驾的逃犯害吽被警察抓整天提心吊膽 (2.61)

liumang weixie $e_{i}$ de taufan, hai pa bei jingcha zhua zhengtian tishindiaodan scamp threaten fugitive be scared of getting caught by the police all day worried 'The fugitive who the scamp threatened is scared of getting caught by the police and is worried all the time.'

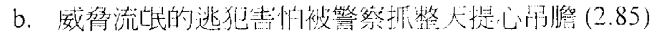

$e_{\text {: }}$ weixie liumang de taufan, hai pa bei jingcha zhua zhengtian tishindiaodan

threaten scamp fugitive be scared of getting caught by the police all day worried 'The fugitive who threatened the scamp is scared of getting caught by the police and is worried all the time.'

c. 流垊威脅的小偷陷害的逃犯害怕被警察抓 (2.55) (2.55)

liumang weixie $e_{i}$ de $x i a o t a o_{i} x i e n h a i e_{k}$ de $\underline{t a u f a}_{k}$ hai pa bei jingcha zhua scamp threaten thief plot against fugitive be scared of getting caught by the police

'The fugitive who the thief who the scamp threatened plotted against is scared of getting caught by the police.'

d. 减妿陷害小偷的流蚟的逃犯害忙被警察抓 (2.85) (2.55)

$e_{i}$ weixie $e_{k}$ xienhai xiaotao de liumang $g_{k}$ de taufan, hai pa bei jingcha zhua threaten plot against thief scamp fugitive be scared of getting caught by the police

'The fugitive who threatened the scamp who plotted against the theif is scared of getting caught by the police.' 
18.

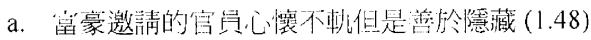

fuhao yaoching $e_{i}$ de guanyuan; shinhuaibugui danshi shanyu yintsang

tycoon invite official have bad intentions but good at hiding

'The official who the tycoon invited has bad intentions but is good at hiding them.'

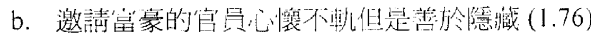

$e_{i}$ yaoching fuhao de guanyuan; shinhuaibugui danshi shanyu yintsang

invite tycoon official have bad intentions but good at hiding

'The official who invited the tycoon has bad intentions but is good at hiding them.'

c. 宫豪邀請的法官勾結的官只心懷不軦 (1.91) (2.27)

fuhao yaoching $e_{i}$ de faguan gojie $e_{k}$ de guanyuan. shinhuaibugui

tycoon invite judge conspire official have bad intentions

'The official who the judge who the tycoon invited conspired with has bad intentions.'

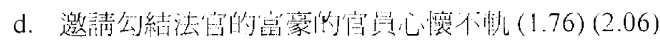

$e_{i}$ yaoching $e_{k}$ gojie faguan de fuhao de guanyuan, shinhuaibugui

invite conspire tycoon judge official have bad intentions

'The official who invited the tycoon who conspired with the judge has bad intentions.'

19.

a. 居民協助的簐官受傷了被䢒往醫院 (1.97)

jumin $x$ iechu $e_{i}$ de junguan, shoushang le bei song wang yiyuan

resident assist soldier get hurt perfe, passive send to hospital

'The soldier who the resident assisted got injured and was sent to the hospital,'

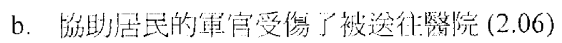

$e_{i}$ xiechu jumin de junguan, shoushang te bei song wang yiyuan

assist resident soldier get hurt perfe. passive send to hospital

'The soldier who assisted the resident got injured and was sent to the hospital.'

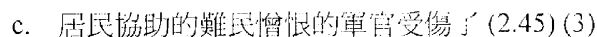

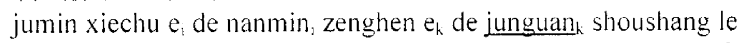

resident assist refugee hate soldier get hurt perf.

'The soldier who the refugee who the resident assisted hates got injured.'

d. 協助憎恨難民的居民的軍管受傷了 (2.06) (2.97)

$e_{i} x i e c h u e_{k}$ zenghen nanmin de jumin $n_{k}$ de junguan, shoushang le

assist hate refugee resident soldier get hurt

'The soldier who assisted the resident who hates the refugee got injured.'

20.

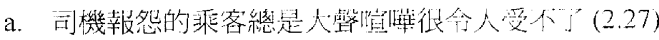

siji baoyuan $\mathrm{e}_{1}$ de chengke $\mathrm{e}_{i}$ zongshi daoshengxuanhua hen lingren shoubuliao driver complain about passenger be always very loud very for people intolerable "The passenger who the driver complained about is always very loud and people can't stand it.'

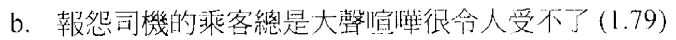

$\mathrm{e}_{\mathrm{i}}$ baoyuan siji de chengke zongshi daoshengxuanhua hen lingren shoubuliao complain about driver passenger be always very loud very for people intolerable 'The passenger who complained about the driver is always very loud and people can't stand it.' 


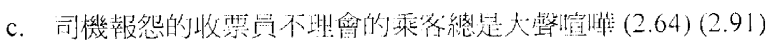

siji baoyuan $e_{i}$ de shoupiaoyuan, bulihue $e_{k}$ de chengke $e_{k}$ zongshi daoshengxuanhua driver complain about ticket collector ignore passenger be always very loud 'The passenger who the ticket collector who the driver complained about ignored is always very loud.'

d. 報怨不理會收䕀筫的问機的乘客總是大聲愃䀨 (1.79) (3.24)

$e_{1}$ baoyuan $e_{k}$ bulihue shoupiaoyuan de siji de chengke, zongshi daoshengxuanhua complain about ignore ticket collector driver passenger be always very loud - The passenger who complained about the driver who ignored the ticket collector is always very loud.'

\section{References}

Bever, T. G., (1970). The cognitive basis for linguistic structures. In J.R. Hayes (Ed.), Cognition and the development of language. New York, Wiley, pp. 279-362.

Chomsky, N., \& Miller, G. A. (1963). Introduction to the formal analysis of natural languages. In R. D. Luce, R. R. Bush, \& E. Galanter (Eds.), (2) (pp. 269-321). Handbook of mathematical psychology, New York: Wiley.

Christiansen, M. H., \& Chater, N. (1999). Toward a connectionist model of recursion in human linguistic performance. Cognitive Science, 23, 157-205.

Desmet, T., \& Gibson, E (in press). Disambiguation preferences and corpus frequencies in noun phrase conjunction. Journal of Memory and Language.

Dowty, D. (1991). Thematic proto-roles and argument selection. Language, 67, 547-619.

Ferreira, F., \& Clifton, C., Jr. (1986). The independence of syntactic processing. Journal of Memory and Language, 25, 348-368.

Fodor, J. D., \& Ferreira, F. (1998). Reanalysis in sentence processing. Dordrecht: Kluwer.

Ford, M. (1983). A method for obtaining measures of local parsing complexity throughout sentences. Journal of Verbal Learning and Verbal Behavior, 22, 203-218.

Gibson, E. (1991). A computational theory of human linguistic processing: Memory limitations and processing breakdown. Unpublished doctoral dissertation, Carnegie Mellon University, Pittsburgh, PA.

Gibson, E. (1998). Linguistic complexity: locality of syntactic dependencies. Cognition, 69, 1-76.

Gibson, E. (2000). The dependency locality theory: a distance-based theory of linguistic complexity. In Y. Miyashita, A. Marantz, \& W. O’Neil (Eds.), Image, language, brain (pp. 95-126). Cambridge, MA: MIT Press.

Gibson, E., \& Pearlmutter, N. (1998). Constraints on sentence comprehension. Trends in Cognitive Science, 2, $262-268$.

Gibson, E., \& Schutze, C. (1999). Disambiguation preferences in noun phrase conjunction do not mirror corpus frequency. Journal of Memory and Language, 40, 263-279.

Grodner, D., Gibson, E., Argaman, V., \& Babyonyshev, M (in press). Against repair-based reanalysis in sentence comprehension. Journal of Psycholinguistic Research.

Grodner, D., Watson, D., \& Gibson, E. (2000). Locality Effects on Sentence Processing. Talk presented at the 13th CUNY sentence processing conference, University of California, San Diego.

Hakes, B., Evans, J., \& Brannon, L. (1976). Understanding sentences with relative clauses. Memory and Cognition, 4, 283-296.

Hale, J (in press). The information conveyed by words in sentences. Journal of Psycholinguistic Research.

He, Y. (1996). An introduction to government-binding theory in Chinese syntax. Lewiston, NY: Edwin Mellen Press.

Holmes, V. M., \& O’Regan, J. K. (1981). Eye fixation patterns during the reading of relative clause sentences. Journal of Verbal Learning and Verbal Behavior, 20, 417-430.

Hsiao, F (2003). The syntax and processing of relative clauses in Mandarin Chinese. $\mathrm{PhD}$ dissertation, Department of Linguistics, MIT, Cambridge, MA. Available through MIT working papers in linguistics (MITWPL). 
Just, M. A., Carpenter, P. A., \& Woolley, J. D. (1982). Paradigms and processing in reading comprehension. Journal of Experimental Psychology: General, 111, 228-238.

Kayne, R. (1994). The antisymmetry of syntax. Cambridge, MA: MIT Press.

Keenan, E. (1985). Relative clauses. In T. Shopen (Ed.), (2). Language typology and syntactic description, Cambridge: Cambridge University Press.

Keenan, E. L., \& Comrie, B. (1977). Noun phrase accessibility and universal grammar. Linguistic Inquiry, 8, 63-99.

Keenan, E. L., \& Hawkins, S. (1987). The psychological validity of the accessibility hierarchy. In E. Keenan (Ed.), Universal grammar: 15 essays (pp. 60-85). London: Routledge.

King, J., \& Just, M. A. (1991). Individual differences in syntactic processing: the role of working memory. Journal of Memory and Language, 30, 580-602.

Lewis, R. (1996). A theory of grammatical but unacceptable embeddings. Journal of Psycholinguistic Research, 25, 93-116.

Li, C., \& Thompson, S. (1981). Mandarin Chinese: a functional reference grammar. Berkeley, CA: University of California Press.

MacDonald, M. C. (1999). Distributional information in language comprehension, production, and acquisition: three puzzles and a moral. In B. MacWhinney (Ed.), The emergence of language. Mahwah, NJ: Erlbaum.

MacDonald, M. C., \& Christiansen, M. (2002). Reassessing working memory: comment on Just and Carpenter (1992) and Waters and Caplan (1999). Psychological Review, 109, 35-54.

MacWhinney, B. (1977). Starting points. Language, 53, 152-168.

MacWhinney, B. (1982). Basic syntactic processes. In S. Kuczaj (Ed.), Syntax and semantics (1). Language acquisition, Hillsdale, NJ: Erlbaum.

MacWhinney, B., \& Pleh, C. (1988). The processing of restrictive relative clauses in Hungarian. Cognition, 29, 95-141.

Mitchell, D. C., Cuetos, F., Corley, M. M. B., \& Brysbaert, M. (1995). Exposure-based models of human parsing: evidence for the use of coarse-grained (nonlexical) statistical records. Journal of Psycholinguistic Research, $24,469-488$.

Pearlmutter, N. J., \& Gibson, E. (2001). Recency in verb phrase attachment. Journal of Experimental Psychology: Learning, Memory, and Cognition, 27, 574-590.

Rohde, D. L. T (2002). A connectionist model of sentence comprehension and production. Unpublished $\mathrm{PhD}$ thesis, School of Computer Science, Carnegie Mellon University, Pittsburgh, PA.

Sturt, P., Pickering, M., \& Crocker, M. (1999). Structural change and reanalysis difficulty in language comprehension. Journal of Memory and Language, 40, 136-150.

Tabor, W., Juliano, C., \& Tanenhaus, M. K. (1997). Parsing in a dynamical system: an attractor-based account of the interaction of lexical and structural constraints in sentence processing. Language \& Cognitive Processes, $12,211-272$.

Tanenhaus, M. K., \& Trueswell, J. C. (1995). Sentence comprehension. In J. Miller, \& P. Eimas (Eds.), Speech, language, and communication. New York: Academic Press.

Trueswell, J. C., Tanenhaus, M. K., \& Garnsey, S. M. (1994). Semantic influences on parsing: use of thematic role information in syntactic disambiguation. Journal of Memory and Language, 33, 285-318.

Wanner, E., \& Maratsos, M. (1978). An ATN approach in comprehension. In M. Halle, J. Bresnan, \& G. Miller (Eds.), Linguistic theory and psychological reality (pp. 119-161). Cambridge, MA: MIT Press.

Warren, T., \& Gibson, E. (2002). The influence of referential processing on sentence complexity. Cognition, 85, 79-112.

Waters, G. S., Caplan, D., \& Hildebrandt, N. (1987). Working memory and written sentence comprehension. In M. Coltheart (Ed.), The psychology of reading (12) (pp. 531-555). Attention and performance, Hillsdale, NJ: Erlbaum. 